\title{
ТЕОРЕТИКО-МЕТОДОЛОГИЧЕСКИЕ АСПЕКТЫ КАТЕГОРИИ «РИСК»: ПАРАДИГМА ТРАНСФОРМАЦИИ
}

\author{
(c) 2018 Янов Виталий Валерьевич \\ доктор экономических наук, профессор, зав. кафедрой «Финансы и кредит» \\ Поволжский государственный университет сервиса \\ 445677, Самарская обл., г. Тольятти, ул. Гагарина, д. 4 \\ E-mail: kaf-fin@tolgas.ru
}

Факторы неопределенности при принятии решений в области управления (в том числе и на стадиях бюджетного процесса) трудно не учитывать. В процессе рыночных преобразований, усиления воздействия вероятностных событий на функционирование экономики, изменился подход к субстанции «риск», в том числе и на стадиях исполнения бюджетного процесса, эффект которого определяется эквивалентностью декларируемых показателей исполнения бюджета с прогнозами. Необходимость решения этой сложной многоаспектной задачи определяется динамично развивающимися процессами российской экономики.

Ключевые слова: риск, финансовый риск, бюджетный риск, ожидаемое исполнение бюджета, риск исполнения бюджета.

Разработка теоретико-методологических аспектов риска и исследование практики его воздействия на хозяйствующие субъекты, особенно при урегулировании процессов невыполнения платежных обязательств между предприятиями актуальны для национальной экономики.

Концептуальные основы риска исследованы разными научными школами: классической (Дж. Милль, Н.У. Секиф), неоклассической (А. Маршалл, А. Пигу), субъективной (В.А. Ойгензихит, Дж. Хэмптом, В.А. Гамза). Риск и вероятность наступления событий, при которых могут возникнуть потери, в результате выбранного решениям в классической теории, понятия тождественные. Концептуальный подход к риску в неоклассической теории определяется, формированием прибыли в условиях непредсказуемости и прогнозируемой ее величины, из множества альтернативных вариантов, предпочтение отдается решению волативность возможной прибыли при котором меньше. Проведенный анализ субъективной концепции риска показывает, что сторонники этой теории выделяют уровни исследования на каждом из которых решаются специфические теоретические задачи, с одной стороны, на уровне сущностных отношений - риск всегда субъективен, поскольку связан с волей и сознанием индивидуума, а, с другой,- на уровне вероятных закономерностей наступления нежелательного для хозяйствующих субъектов событий из многообразия альтернативных вариантов.
Соотношение риска как количественного несоответствия между ожидаемым и фактическим доходом исследовались французскими и немецким экономистами Р. Контильоном, И. фон Тюнен. Попытка уменьшения вероятностной оценки неопределенности, позволяет расширить область управляемого риска и увеличение вариантов получения более высокой прибыли.

Таким образом, несмотря на множество различных трактовок риска, в рамках рассматриваемых концепций, на наш взгляд, отсутствует единая позиция среди российских и зарубежных исследователей на его сущность и критерии оценки. В связи с этим, сомнения в безупречности характеристик риска в трактовках выше обозначенных авторов вполне обоснованы. Наличие разнообразных критериев риска дает основание выделить следующие концептуальные подходы:

- толкование сущности риска как вероятностных потерь в процессе достижения цели;

- интерпретация риска как способность хозяйствующего субъекта функционировать в трансформирующихся экономических условиях, критерием которого является величина ожидаемой прибыли и выбор варианта в котором волатильность прибыли будет меньше;

- трактовка риска как категории субъективной, предполагающей обеспечение максимального уровня удовлетворения потребностей субъектов, руководствующихся собственными целями при выборе альтернативных вариантов; 
- толкование риска на основе абстрагирования от конкретного понимания и необходимости четкого разграничения риска и неопределенности.

Критериальные подходы, интерпретированные в табл. 1, дают возможность прогнозировать тенденции риска:

- на мезоуровне величину масштабности вероятного риска, выражаемую количеством хозяйствующих субъектов на территории региона и объемами реализации продукции в валовом региональном продукте;

- на микроуровне применение между ссудополучателями и кредиторами разнообразных форм расчетов по долговым обязательствам, в каждом из которых сопоставляется риск, приемлемый для участников кредитной сделки с ожидаемым доходом, персонификацией субъектов хозяйствования на основе содержания и направленности их экономических интересов.

Исследование риска в отечественной экономической науки является предметм постоянного внимания. Специфические черты риска фор- мирующиеся, например, в финансовом сегменте экономики определяется:

- существованием менее ликвидных активов по размещению ссуд в отличие от ценных бумаг, которые более свободно обращаются на фондовом рынке;

- различным содержанием кредитных договоров заключаемых коммерческими банками с судополучателями и держателями временно свободных денежных средств ссудодателями.

Классификация рисков была рассмотрена Дж.М. Кейсом, который все риски разделил на группы: риск предпринимателя - заемщика, ожидающего неопределенность в получении предполагающего дохода от инвестиционной деятельности; риск ссудодателя - риск невозврата кредита, включающегося риск уклонения от погашения ссуды и риск не ликвидности обеспечения; риск потери денежных средств в результате высокой волативности денежной единицы. В последующих исследованиях российских и зарубежных экономистов классификация рисков, была разработана более подробно.

\section{Таблица 1. Научные трактовки категории «риск»}

\begin{tabular}{|c|c|c|c|c|}
\hline \multirow[b]{2}{*}{$\begin{array}{c}\text { Критериальные } \\
\text { подходы к понятию } \\
\text { «риск» }\end{array}$} & \multicolumn{4}{|c|}{ Исследователи, стоящие на позициях определенных концепций и их содержание } \\
\hline & $\begin{array}{l}\text { Дж. Милль, } \\
\text { Н.У. Секиф }\end{array}$ & $\begin{array}{l}\text { А. Маршалл, } \\
\text { А. Пигу }\end{array}$ & $\begin{array}{c}\text { В.А. Ойгензихит, } \\
\text { В.А. Гамза, } \\
\text { Дж. Хэмптон }\end{array}$ & $\begin{array}{l}\text { Р. Кантильон, } \\
\text { И. фон Тюнен }\end{array}$ \\
\hline $\begin{array}{c}\text { Вероятность потерь } \\
\text { и риска тождествен- } \\
\text { ные субстанции }\end{array}$ & $\begin{array}{c}\text { Риск отождествле- } \\
\text { ния с вероятностью } \\
\text { потерь, которые } \\
\text { могут произойти в } \\
\text { результате выбран- } \\
\text { ного решения }\end{array}$ & & & \\
\hline $\begin{array}{c}\text { Риск трактуется как } \\
\text { предельная полез- } \\
\text { ность }\end{array}$ & & $\begin{array}{c}\text { Риск рассматрива- } \\
\text { ется как предельная } \\
\text { полезность воз- } \\
\text { можных колебаний } \\
\text { размера ожидаемой } \\
\text { прибыли без учета } \\
\text { ожидаемых убытков }\end{array}$ & & \\
\hline $\begin{array}{c}\text { Риск всегда субъ- } \\
\text { ективен поскольку } \\
\text { предполагает со-- } \\
\text { знательный выбор } \\
\text { из альтернативных } \\
\text { вариантов }\end{array}$ & & & $\begin{array}{c}\text { Субъективность } \\
\text { риска формиру- } \\
\text { ется в результате } \\
\text { оценки человеком, } \\
\text { явлений, действий, } \\
\text { как сознательный } \\
\text { выбор возможных } \\
\text { альтернатив }\end{array}$ & \\
\hline $\begin{array}{c}\text { Риск как количе- } \\
\text { ственное выраже- } \\
\text { ние несоответствия } \\
\text { между ожидаемым } \\
\text { и фактическим } \\
\text { доходом }\end{array}$ & & & & $\begin{array}{c}\text { Риск и неопреде- } \\
\text { ленности-понятия } \\
\text { нетождественные. } \\
\text { Причина риска в } \\
\text { неопределенности. } \\
\text { Неопределенность } \\
\text { источник прибыли } \\
\text { или убытка. }\end{array}$ \\
\hline
\end{tabular}


Развитие рыночных отношений в экономике, предполагающей конкуренцию между хозяйствующими субъектами, диверсификацию инвестиционной деятельности и прозрачности инфраструктурных отношений предполагает уменьшение воздействие непрогнозируемого риска, в том числе, финансового. Потенциальные финансовые риски, возникающие в процессах трансформации активов, уменьшаются за счет концентрации возможностей при реализации трансакционных технологий.

Другой важной причиной существования финансового риска является фактор информационной ассимметрии, заключающейся в дифференцированных для различных хозяйствующих субъектов возможностей доступа к информационным ресурсам, что является источником преференций для одних и потерь- для других. Отсутствие равноценного доступа к достоверной финансовой информации порождает специфический риск, связанный с увеличением трансакционных издержек. Каждый субъект хозяйствования имеет возможность аккумулировать и анализировать финансовую информацию, создавать условия для мотивации потенциальных инвесторов, размещать временно свободные активы. Вместе с тем, риск роста затрат, связанный с изучением информации, полученных из открытых финансовых источников, будет выше, чем риск увеличения издержек хозяйствующего субъекта, имеющего преференции в результате доступа к информационным ресурсам.

Систематизация классификационных критериев, видов рисков имеет важное значение как для научной, так и практической деятельности, в сфере управления рисками, в том числе, финансовыми. Исследование научных подходов к пониманию финансового риска позволяет углубить его содержание в субъектно-объектном, функционально- процессном и организационнопроцедурном аспектах и развивать концепцию финансового риска в целом.

В субъектно-объектном аспекте, финансовый риск - это объективная экономическая категория, сущностное содержание которой проявляется, в виде совокупности экономических отношений возникающих при движении финансовых потоков денежных средств, связанных с каким либо активом, а, с другой стороны, в виде вероятности отклонения от декларированного результата. Исходя из этого, специфика финансового риска проявляется в отношениях между двумя субъектами: хозяйствующего субъекта и финансовым посредником (коммерческим банком), способствующие в условиях рыночной неопределенности, уменьшению риска за счет рационального поведения, перераспределения рисков между участниками финансовых отношений.

Финансовый риск, с точки зрения функционально-процессного подхода, предполагает: персонификацию участвующих в нем субъектов на основе содержания и вероятностного вектора направленности финансового риска, роста интенсивности конкуренции на финансовом рынке между банками и небанковскими финансовыми и нефинансовыми организациями, активизировавших процессы консолидации финансовых ресурсов в форме слияний, поглощений с целью укрепления конкурентных позиций и их участие в формировании баланса интересов между участниками рыночных отношений. Финансовый риск зависит от формирования прогрессивный динамики вероятностных событий на уровне мезо-и микроэкономики и учета баланса интересов как ссудодателей, так и интересов, преследующих целей разнонаправленного характера: первый стремится получить максимум денежных средств, второй- минимизацию вероятностных потерь при инвестиционной деятельности.

В контексте организационно-процедурного подхода финансовый риск представляет взаимосвязанное единство таких составляющих как устойчивый характер взаимодействия субъектов хозяйственной деятельности и общей субстанции финансового риска, являющейся основой прогнозирования вероятностных направлений конъюктурного характера. Причинами трансформации конъюктурных направлений могут выступать структурные изменения на финансовых рынках:

- дерегулирование финансово-кредитной деятельности, практическими завуалировавшее институциональные разграничения между различными видами банковской и финансовой деятельности;

- глобализация финансовых рисков и развитие цифровой экономики.

Идентифицирование и систематизирование финансовых рисков позволяет определить место каждого риска в экономической системе и создает предпосылки применения комбинации различных методов управления риска- 
ми. Использование теоретических подходов в практической деятельности применительно к управлению рисками необходимо различать его субстанционное существование и процесс его функционирования. Сложность овладения последним заключается в необходимости изучения закономерных связей, не имеющих однозначной детерминации, не только на уровня макро,- микроэкономики, но и экономических отношений, возникающих на мезоуровне.

Основными причинами возникновения финансовых рисков является нестабильность финансовых рынков, усиление влияния внешнеэкономической деятельности, в форме экономических санкций западных стран в отношении РФ, завоевания новых сфер влияния на международных рынках, особенно экспорта сырьевых ресурсов, изменение курсов валют, рост инфляционных ожиданий, динамичное развитие цифровой экономики. Большая часть существующих определений, финансового риска связано с осуществлением какой- либо финансовой деятельности (табл. 2).

Таким образом, финансовым можно назвать риск, возникающий при движении потоков денежных средств и связанный с каким-либо активом. Финансовый риск - это вероятность отклонения от прогнозируемого результата, возможность получения не только убытков, но и дополнительной прибыли в результате осуществления какой-либо финансовой деятельности.

Трансформационные преобразования в российской экономике способствовали, дальнейшему развитию категории финансового ри-

Таблица 2. Современные теоретические подходы к пониманию категории «финансовый риск»

\begin{tabular}{|c|c|c|c|c|c|}
\hline \multirow{2}{*}{$\begin{array}{c}\text { Критерии, отра- } \\
\text { жающие пони- } \\
\text { мание финансо- } \\
\text { вого риска }\end{array}$} & \multicolumn{5}{|c|}{ Авторы научных взглядов и их трактовки финансового риска } \\
\hline & $\begin{array}{l}\text { Кудрявцев М.А. } \\
\text { и Королёв А.Ю. }\end{array}$ & Литовских А.М. & Уткин Э.А. & Рожков Ю.В. & $\begin{array}{c}\text { Рэдхэд К., } \\
\text { Хьюс С. }\end{array}$ \\
\hline $\begin{array}{c}\text { Риск на фр- } \\
\text { ндовом рынке } \\
\text { ценных бумаг }\end{array}$ & $\begin{array}{c}\text { Вероятные по- } \\
\text { тери хозяйству- } \\
\text { ющего субъекта } \\
\text { при осущест- } \\
\text { влении деятель- } \\
\text { ности на рынке } \\
\text { ценных бумаг }\end{array}$ & & & & \\
\hline $\begin{array}{l}\text { Риск потери де- } \\
\text { нежных средств }\end{array}$ & & $\begin{array}{c}\text { Вероятность } \\
\text { потери денеж- } \\
\text { ных средств в } \\
\text { результате не- } \\
\text { благоприятной } \\
\text { конъюнктуры }\end{array}$ & & & \\
\hline $\begin{array}{c}\text { Риск по опера- } \\
\text { циям предприя- } \\
\text { тий и финансо- } \\
\text { вых институтов }\end{array}$ & & & $\begin{array}{l}\text { Риск, возникаю- } \\
\text { щий вследствие } \\
\text { отношений } \\
\text { хозяйствующего } \\
\text { субъекта с бан- } \\
\text { ками и другими } \\
\text { финансовыми } \\
\text { институтами }\end{array}$ & & \\
\hline $\begin{array}{c}\text { Риск возника- } \\
\text { ющий под вли- } \\
\text { янием различ- } \\
\text { ных внешних } \\
\text { и внутренних } \\
\text { факторов. }\end{array}$ & & & & $\begin{array}{c}\text { Вероятность - } \\
\text { получения убыт- } \\
\text { ков или потери } \\
\text { части прибыли } \\
\text { в результате } \\
\text { воздействия ин- } \\
\text { фляции, измене- } \\
\text { ния валютного } \\
\text { курсаи т.д. }\end{array}$ & \\
\hline $\begin{array}{c}\text { Риск по финан- } \\
\text { совым опера- } \\
\text { циям }\end{array}$ & & & & & $\begin{array}{c}\text { Возможность } \\
\text { недополуче- } \\
\text { ния прибыли } \\
\text { (убытки) при } \\
\text { осуществлении } \\
\text { финансовых } \\
\text { операций }\end{array}$ \\
\hline
\end{tabular}


ска применительно к современным условиям. Ссудодатель может своевременно не получить средства с должника. При инфляции платежный спрос на основе средства падает из-за нехватки у хозяйствующих субъектов достаточного объема оборотного капитала, вследствие этого разрушаются долгосрочные хозяйственные связи между предпринимателями-партнерами, а сохраняющиеся отношения в силу объективной необходимости между предприятиями - смежниками, порождают взаимные долги, которые не погашают в срок из-за отсутствия денежных средств. Увеличение оборотных средств за счет ссуд коммерческих банков хозяйствующим субъектам не всегда выгодны из-за высокой процентной ставки. Завышение по отношению к платежеспособному спросу цены на продукцию, в свою очередь, формируют дополнительный источник риска неплатежей, в следствии которых:

- замедляется финансовый и товарный оборот;

- искажаются рыночные сигналы, определяющие экономическую мотивацию решений на микроуровне: с одной стороны, хозяйствующие субъекты оказываются не в состоянии определить реальный платежеспособный спрос на свою продукцию, а с другой, не имеют возможности адекватно оценить собственное финансовое положение, поскольку значительная часть их активов составляют неплатежи, и как следствие - спад производства и несбалансированная ценовая политика субъектов хозяйствования.

В систему финансового риска входит множество видов рисков, связанных с ведением финансовой деятельности: кредитный, банковский, бюджетный, страховой, риск ликвидности, налоговый, инфляционный и другие. Риск, связанный с бюджетом, рассматриваемым как форма образования и расходования фонда денежных средств, предназначенных для финансового обеспечения задач и функций государства, местного самоуправления, занимает важное место в системе финансовых рисков обладает всеми признаками вероятной категории.

Применительно к категории бюджетный риск можно выделить ряд методологических подходов: разграничение вещественного содержания и стоимостной формы; единство объективного (отражение действующей практики воздействия рисков) и субъективного (процесса их познания) и в соответствии с познанной сущно- стью, сознательного управления ими, диалектического единства риска как формы проявления случайных, непредвиденных событий и самих событий вероятностного характера как содержания риска, являющиеся основанием для прогнозирования появления новых форм рисков в функционировании хозяйствующих субъектов.

Экономическая природа бюджетного риска проявляется в процессе формирования доходов и осуществления расходов соответствующего бюджета и характеризуется возможными их отклонениями от планируемого объема. Риск бюджета определяется как вероятное его исполнение по сравнению с прогнозируемыми показателями, соответственно паритетное соотношение между доходной и расходной частью бюджета, окажется безрисковым, финансовый план (бюджет), исполнение которого отличается от паритетного будет рисковым. Фактическое исполнение бюджетов различных уровней, кроме безрисковых, может отличатся от ожидаемого исполнения: чем больше изменчивость бюджета, тем выше риск. Ожидаемое исполнение бюджета по доходам состоит из двух частей. Первая часть - это нормальное, или ожидаемое, исполнение бюджета, зависящее от информации, которой владеют органы государственного и муниципального управления. К показателям, определяющим ожидаемое исполнение бюджета, относятся: темп прироста ВВП, уровень инфляции, ключевая ставка и другие показатели прогноза социально-экономического развития; структура налогов в соответствии с их классификацией, действующей на основе нормативных актов, установленных на данный момент; расчеты поступлений доходов бюджета по подразделениям бюджетной классификации с учетом инфляции и т.д.

Вторая часть вероятностного исполнения бюджета - это неопределяемая, или рисковая часть, формируемая под воздействием непрогнозируемой информации в течении года: вероятное повышение тарифов на продукцию и услуги естественных монополий; катастрофы, особенно техногенные; исполнение доходной части бюджета за счет целевого финансирования; возможность проведения «теневых» экономических операций; несоблюдение налоговой дисциплины собственников и управляющих предприятий по уплате налоговых платежей в бюджет; практика осуществления расчетов за реализованную продукцию через счета специ- 
ально создаваемых структурных подразделений и «третьих лиц. Рисковую часть исполнения бюджета можно разделить на два направления. Первое -связано с постоянным риском, влияющего на большое количество доходных источников или платежей бюджета. Второе направление рискового исполнения бюджета - это непостоянный риск, оказывающий влияние на небольшую часть доходов бюджета. В качестве примера непостоянного риска может рассматриваться чрезвычайная ситуация, вызванная природными явлениями в отдельном регионе, которая влияет на отдельно взятый бюджет и является событием единичным.

Таким образом, при подходе к проблеме рассмотрения понятия бюджетного риска целесообразно рассматривать обе части бюджета в единстве, а не каждую часть самостоятельностью. Под бюджетом понимается форма образования и расходования фонда денежных средств, предназначенных для финансового обеспечения задач и функций государства и местных органов самоуправления. На основании вышеизложенного, можно дать следующее уточненное определение бюджетного риска - это риск, возникающий вследствие отклонений от плановых заданий на стадии исполнения бюджета. Величина степени отклонения плана от факта является показателем уровня бюджетного риска. Бюджетный риск на основе данного определения рассматривается на стадии исполнения бюджета предыдущего года и позволяет учитывать и рассчитывать его при составлении прогноза на следующий временной интервал. Следовательно, необходимость разработки теоретических подходов и рекомендации по совершенствованию регулирования финансовых рисков, в том числе его составной части бюджетных рисков, в процессе исполнения бюджетов на микро,- мезо,- макро уровне требуют как дальнейшего исследования методологических и методических подходов и поиска эффективных методов уменьшения рисков.

\section{Библиографический список}

1. Ковалева Т.М. «Принципы формирования эффективной и конкурентоспособность бюджетной политики государства [Текст] //экономические науки. 2013. № 4(101). С. 121-125.

2. Гамукин В.В. Объективная непредсказуемость как фактор бюджетного риска / В.В. Гамукин // Казанский экономический вестник. 2015. № 4(18). С. 71-78.

3. Воеводская Н.П. Зарубежный опыт оценки банковских рисков // Экономические науки. 2016. № 7 (140). С. 93-96.

4. Кудрин А.Л. Бюджетная политика и источник экономического роста [Текст] А.Л. Кудрин // Вопросы экономики. 2017. № 10.

5. Доева Ф.Н. Регулирование финансовых рисков в банковском секторе России в условиях нестабильности экономики // Экономические науки. 2017. № 12 (157). С. 59-64. 